\title{
Aproximación a los fondos documentales de los procesos de transición política y regionalización en Castilla y León
}

\author{
Manuel Redero San Román, Tomás Pérez Delgado Y José Miguel \\ SÁNCHEZ ESTÉVEZ
}

\section{INTRODUCCIÓN}

Es ya muy numerosa la bibliografía general existente sobre el proceso de Transición a la democracia en España. Incluso existen ya no pocos estudios sobre aspectos concretos de la misma, o sobre determinadas zonas geográficas.

Por eso pensamos que tiene interés ocuparse de la descripción y el análisis de algunos conjuntos documentales existentes en Castilla y León, referentes tanto a la Transición democrática, como al proceso de consolidación de la misma, que guarda estrecha relación con la singladura autonómica.

El marco geográfico de nuestro estudio lo constituyen las provincias integrantes de la actual Comunidad Autónoma de Castilla y León.

Cronológicamente, nuestra búsqueda se centra fundamentalmente en los años setenta y comienzo de los ochenta, etapa en la que se sitúan la crisis final del franquismo, la Transición democrática y el comienzo de la fase autonómica.

Esta última se abre, para Castilla y León, con la concesión de la Preautonomía (13 de junio de 1978) y encuentra su momento definitorio con la aprobación del Estatuto de autogobierno del 2 de marzo de 1983.

Concebimos el cambio político de la Transición como la resultante de un proceso impulsado desde el propio Estado franquista, obligado tras la muerte del dictador a reformar sus estructuras y a integrar las demandas democratizadoras de un amplio segmento de la sociedad española, representado por los partidos y sindicatos democráticos y por el movimiento a favor del autogobierno de las nacionalidades históricas. 
Es bien conocido que la complejidad del Estado franquista tiene mucho que ver con las políticas de reforma y racionalización administrativa, llevadas a cabo desde la década de los sesenta y que fueron implementadas por la misma élite tecnocrática que dirigió el desarrollo económico. Desarrollo económico y reforma administrativa son, pues, los factores responsables de la modernización y consiguiente complejidad adquiridas por la sociedad y el Estado españoles. Ambos son los que permiten explicar la relativa, pero también decisiva autonomia, que ese Estado llegó a tener frente a las clases y sectores sociales que le habían servido de apoyatura en sus inicios, si bien la representación de los intereses de aquellos grupos no era orgánica ni tenía cauces directos de articulación.

Es por eso que pudieron existir personas y grupos que, dentro de aquel Estado, ejercieron funciones de intermediación desde la esfera pública sobre la competencia entre los distintos agentes políticos y sociales en presencia, posibilitando así la reconducción de las ansias democratizadoras, expresadas por la oposición, y la eliminación de la amenaza de desbordamiento social que podía acompañar al proceso de cambio político ${ }^{1}$.

Creemos que es interesante aplicar a Castilla y León semejante forma de ver la Transición; aunque, eso sí, como mera concreción geográfica del tal proceso, pues es evidente que ni por su demografía, ni por su peso económico o proyección política, esta región puede ser considerada como elemento decisivamente condicionador del proceso general.

Sin embargo, conviene hacer este ejercicio sobre un territorio que, pese a su rancia centralidad en la conformación del Estado español y en la construcción ideológica que acompañó a este, ha acabado por ocupar una posición marcadamente periférica en la vida española, contemporáneamente con el despertar de las llamadas nacionalidades históricas?

Ciertamente estamos todavía bastante próximos a los procesos políticos abiertos en España a partir de 1975. Pero eso, en lugar de ser una dificultad para el historiador, pensamos que debe convertirse en un acicate de su tarea, tanto más cuanto que el paso del tiempo va alejando del estudio de los mismos a otros muchos profesionales de las ciencias sociales; incluso, en la conciencia colectiva de los españoles, tales procesos comienzan a vislumbrarse ya con la lejanía cronológica insita en la palabra «historia».

\footnotetext{
Redero San Roman, M. Transición a la democracia y poder politico en la España postfranquista (1975-1978). Salamanca: Libreria Cervantes, 1993

2 SAnchez Estévez, J.M. “Castilla y León en la época contemporánea: Periferización económica. Contrarrevolución. Transición política». Rvta. AULA, vol. V, 1993, pp. 83-104.
} 
Por eso, como tan acertadamente ha señalado el profesor Julio Aróstegui ${ }^{3}$, no hay que considerar que exista una tajante separación entre el campo de trabajo del historiador y el tiempo más próximo, pues no existe cesura «entre lo pasado como materia histórica y lo presente como proceso en fluencia, abordable historiográficamente».

Ante la obvia dificultad de describir todos los fondos documentales de Castilla y León susceptibles de ofrecer información sobre la Transición Política y Proceso de Regionalización consiguiente, hemos decidido ceñirnos a algunos tipos de archivos que, a nuestro juicio, son los más significativos para el objeto de nuestro trabajo. Los hemos agrupado en dos categorías:

- Públicos y/o institucionales: Archivos de las Cortes y Junta de Castilla y León, del Centro Regional de TVE, del Gobierno Civil de Valladolid, Archivo Histórico Provincial de Salamanca y Archivos Locales: Diputación y Ayuntamiento de León.

- Privados: Pertenecientes a algunas fuerzas políticas y sociales del momento: PSCL-PSOE, PREPAL, Archivos Sindicales (Archivo Histórico de la Unión Regional de CCOO). Asimismo, los pequeños archivos de dos profesores cierran este elenco.

En esta selección coexisten archivos de la administración periférica del Estado, archivos de ámbito autonómico, provincial y local ${ }^{4}$, ubicados en Valladolid, León, Salamanca, Zamora y Burgos.

Tal variedad de tipos de archivos y la diversidad de su localización geográfica, puede constituir una muestra suficientemente representativa de los fondos documentales existentes en nuestra región para el estudio de los procesos históricos antedichos.

\section{ARCHIVOS DE LAS INSTITUCIONES REGIONALES: CORTES Y JUNTA DE CASTILLA LEÓN}

Aprobada definitivamente en el Congreso (22 de febrero de 1983) y publicada en el “B.O.E.". La Ley Orgánica 4/1983, de 25 de febrero, del

3 ARostegui, J.: “Sociologia e Historiografia en el Análisis del Cambio Social Reciente". HISTORIA CONTEMPORÁNEA N ${ }^{\circ} 4$ (1990), p. 146. TUSELL, J.: "Historia y Tiempo Presente", CLAVES, $n^{\circ}$ 31, 1993, pp. 54-56; CUESTA, J. Historia del Presente. Madrid: Eudema, 1993.

"BARREIRO, XOSE R.:"Historia regional y fuentes archivisticas", en STUDIA HISTORICA. HISTORIA CONTEMPORÁNEA, vol. VI-VII, 1988-89, pp.55-67; LOPEZ GOMEZ, P.: "Las fuentes documentales de los archivos regionales y provinciales", ibid., pp. 225-248. 
Estatuto de Autonomía de Castilla y León, se convocaron elecciones a las primeras Cortes regionales ${ }^{5}$ para el 8 de mayo de 1983 , cuyos escaños se repartieron entre PSCL-PSOE 42 procuradores, CD (AP-PDPUL) 39 procuradores, CDS 2 procuradores y PDL 1 procurador; no obtuvieron representación el PCE, ni las formaciones de carácter regionalista ${ }^{6}$.

Celebraron su sesión constituyente en la Villa de Tordesillas el 21 de mayo, fijando provisionalmente su sede en Fuensaldaña (Valladolid), que acabó siendo su emplazamiento definitivo. Se abrió el curso político normal el día 25 de octubre de ese año, con la presentación por todos los Consejeros de la Junta - ejecutivo formado por el PSCL/PSOE, que también desde el 12 de agosto se había trasladado a Valladolid- de sus respectivos programas ante las correspondientes Comisiones Informativas.

Hasta entonces, la conformación y primera andadura de los entes preautonómicos (Junta de Consejeros y Pleno del Consejo actuaban prácticamente como Ejecutivo y legislativo), estuvo condicionada por el debate de la ubicación de las instituciones ${ }^{?}$.

Naturalmente, esta situación de indefinición no favoreció el adecuado funcionamiento de las mismas $y$, por lo que respecta al tema que nos ocupa, también repercutió sobre la tardía recopilación de los fondos documentales y de su regulación normativa.

\section{Archivo de las Cortes de Castilla y León}

La Ley 6/1991, de 19 de abril, de Archivos y Patrimonio Documental de Castilla y León, establece en su Art”. 32: “El Archivo de las Cortes de

Aguado Renedo, C. "Características y composición de las Cortes de Castilla y León, según el Estatuto de Autonomia”. En: Las Cortes de Castilla y León 1188-1988, vol. II. Valladolid, 1990, pp. $665-677$

- La débil articulación del regionalismo quedó de manifiesto en estas primeras elecciones regionales, ya que tan sólo una coalición autóctona de agrarios y leonesistas (BAR- PREPAL) trató de cubrir todo el territorio Castellano-leonés, obteniendo 25.566 sufragios $(1,8 \%)$. El resto de las formaciones no estatales que concurrieron se limitaron a los ámbitos provinciales: Unión Leonesista y Partido del Bierzo en León, Solución Independiente en Burgos, Unidad Comunera Castellana en Palencia (Anuario EL PAIS 1984, pp. 109-110).

7 Las ciudades de Burgos y León se propugnaron como capitales alternativas al eje Tordesillas-Valladolid, incluso se pensó en un reparto: el ejecutivo en Valladolid, las Cortes en Burgos o León. Hasta el 29 de diciembre de 1987 no quedaron confirmadas, por Ley, las sedes de la Junta y Cortes en Valladolid y la del Tribunal Superior de Justicia de la Comunidad en Burgos. (Rivero YSERN, E., dir. Comentarios al Estatuto de Autonomia de Castilla y León. Ministerio de Administraciones Públicas: Madrid, 1985, pp. 44-45 y 55-64. ANUARIO DE CASTILLA Y LEÓN 1993. Valladolid: Ambito, 1993, pp. 38 y 49). 
Castilla y León se encargará de recoger, conservar, organizar y comunicar la documentación generada o reunida por los órganos parlamentarios de la Comunidad Autónoma". Y, en efecto, pese a las carencias iniciales, allí se encuentran bien clasificados e informatizados los siguientes fondos:

- Boletín Oficial del Consejo General de Castilla y León, desde el no. 1, que recoge el R.D.- Ley 20/1978 de 13 de junio por el que se aprobaba el Régimen Preautonómico, hasta el $n^{\circ} 15$ (del 30 de mayo de 1983) que cerraba la gestión del Consejo General.

Su estructura difiere sustancialmente del posterior Boletín Oficial de las Cortes: se entremezclan medidas propiamente ejecutivas 0 "de gobierno" (acuerdos de la Junta de Consejeros, nombramientos o disposiciones de las Consejerías) con las deliberaciones, por ejemplo, del Proyecto de Estatuto o normativas que corresponderian a un parlamento; pero es una fuente esencial para seguir la primigenia conformación de esta Comunidad Autónoma.

- El Boletín Oficial de las Cortes de Castilla y León. Presenta el sumario habitual de los órganos legislativos: proyectos y proposiciones de ley, con las enmiendas y votos particulares de los procuradores y grupos, informes de ponencia, dictámenes de Comisiones, interpelaciones y mociones, proposiciones no de ley, propuestas de resolución, decisiones de la Mesa de las Cortes y comunicaciones de la Junta de Castilla y León «y cualquier otro texto o documento cuya publicación sea exigida por algún precepto de este Reglamento o lo ordene el Presidente, atendiendo a la exigencia de un trámite que requiera la intervención de las Cortes de Castilla y León. También publicará, a juicio de la Presidencia, las disposiciones de las Cortes Generales del Estado que puedan afectar a la Comunidad Autónoma de Castilla y León" [Art. 64 del Reglamento de las Cortes, BOCL $n^{\circ} 45$, de 5 de marzo de 1990]. Resulta, por tanto, muy útil para estudiar el desarrollo estatutario orgánico en el marco del Estado y trazar una perspectiva comparada con otras Comunidades Autónomas.

- Diario de Sesiones, regulado en su conformación por disposición del Reglamento de las Cortes. Reproduce integramente todas las intervenciones y acuerdos del Pleno, de la Diputación Permanente y de las Comisiones; levanta, asimismo, acta literal de las sesiones secretas, "cuyo único ejemplar se custodiará en la Presidencia», publicándose en el Diario sólo los acuerdos adoptados [Art. 63 de dicho Reglamento, BOCL $n^{\circ} 45$, de 5 de marzo de 1990].

- Memorias anuales y Cuadernos trimestrales de Información Parlamentaria, interesantes para valorar la actividad de las Cortes (proyectos en trámite, reuniones y sesiones) y las relaciones de estas con los otros poderes políticos, administrativos e, incluso, sociales. 
En definitiva, este material documental del Archivo y Biblioteca de Fuensaldaña resulta imprescindible para conocer la andadura de las Cortes $^{8}$, el pulso político real y la problemática de Castilla y León, que se reflejan en los grandes debates sobre presupuestos, estado de la Región, investidura del jefe del ejecutivo, etc. También es útil para seguir las relaciones con el Gobierno de la Nación y los parlamentos de otras autonomías, así como la incidencia de las políticas eurocomunitarias sobre los sectores económicos regionales.

\section{Archivo Central de la Junta y de la Administración Autonómica de Castilla y León ${ }^{9}$}

En el período preautonómico, las reuniones del Pleno (órgano supremo de representación del Consejo de Castilla y León) y de la Junta de Consejeros (órgano ejecutivo de aquél) eran itinerantes. Aunque la Secretaria General trataba de registrar y concentrar la documentación en la teórica sede provisional de la Presidencia (el Palacio de la Isla en Burgos), las Consejerías (luego Departamentos) comenzaron su andadura en despachos cedidos por las Diputaciones de las provincias en las que residia cada uno de sus titulares. Ni que advertir tiene que la recuperación de los fondos relativos al Consejo de Castilla y León desde su formación, constituyó una tarea particularmente árida: "Baste decir que la primera documentación que se custodia en el Archivo, no llegó a nosotros de la forma habitual en que es recibida en otros archivos, por transferencias documentales, sino que se hizo al cambiar la Sede de la Junta de Burgos a Valladolid [la

\footnotetext{
8 Elorza Guinea, J. C. Las Cortes actuales de Castilla y León: Diez años de Estatuto de Autonomia. Edic. Cortes de Castilla y León: Valladolid, 1993

9 Según lo dispuesto en el Art. 31 de la Ley 6/1991, de Archivos y del Patrimonio Documental de Castilla y León; se crea el Archivo General de Castilla y León con la finalidad de recoger, conservar, organizar, comunicar y difundir «la documentación producida y reunida por los órganos centrales del Gobierno y de la Administración de la Comunidad Autónoma y por los organismos Administrativos del ámbito autonómico ya extinguidos..." y para "los fondos documentales históricos de interés general..."

Se establecen archivos de tipo intermedio en la Presidencia de la Junta y cada una de las Consejerias; finalmente, en cada provincia existirá un Archivo Territorial, "único para las Delegaciones y Servicios de la Junta...", que mantendrá la documentación "hasta su transferencia a los Archivos Históricos Provinciales" (Arts. 34 y 35 ). En las disposiciones transitorias $2^{\mathrm{a}}$ y $3^{\mathrm{a}}$, se establece el cambio de denominación del Archivo Central de la Administración de Castilla y León por Archivo Central de la Consejeria de Presidencia y Administración Territorial, el cual mientras nos se disponga de la infraestructura para poner en marcha los archivos creados arriba, "funcionará como Archivo General de Castilla y León y ... como Archivo Central de las diferentes Consejerías."
} 
decisión se tomó el 12 de agosto de 1983]. Como es lógico pensar, no existian Hojas de Transferencia firmadas por el organismo emisor. ${ }^{10}$.

Pese a estos condicionamientos, altas dosis de empeño y competencia profesional hicieron factible la publicación por Ma . Carmen Gandia, del INVENTARIO DE DOCUMENTACIÓN DEL CONSEJO GENERAL DE CASTILLA Y LEÓN (1978-1983), instrumento imprescindible de consulta y guia: Incluye una introducción sucinta sobre la tortuosa historia de la Preautonomia y especifica el organigrama de funcionamiento del Pleno del Consejo y Junta de Consejeros, Junta de Dirección, Presidencia y Secretaria General, Comisiones Delegadas y Consejerías (luego Departamentos) y su evolución.

El tratamiento que se le dio a los fondos documentales inventariados, en soporte informático DBASE, permite la búsqueda documental múltiple: organismo (secciones), suborganismo (series), signatura (número de Caja $y$ orden dentro de la misma), lugar y fecha -lamentablemente en algunos escritos faltan ambas-, tipologia documental (Estatuto, Reglamento, decretos, presupuestos, actas de reuniones, propuestas, informes, nomenclator provinciales, oficios, reclamaciones, noticias, notas, artículos de prensa, cartas, expedientes, programas de trabajo y ponencias, acuerdos, etc.) y, finalmente, los contenidos.

Un indice bastante completo de organismos, lugares, personas y materias facilita el manejo de este inventario.

Las series documentales permiten al historiador trabajar sobre los temas siguientes:

A) Estructuración y primeros pasos de la Administración Preautonómica, relaciones con los órganos del Estado (Ministerios, Cortes Generales, Gobiernos Civiles) y con las entidades locales (Diputaciones y Ayuntamientos). Resultan particularmente interesantes los datos que se recababan sobre la marcha de otras autonomías y la "respuesta" de los castellano-leoneses, desde las instituciones o la calle, a la nueva situación.

10 Gandia Martinez, M. C.: Inventario de Documentación del Consejo General de Castilla y León (1978-1983). Ed. Junta de Castilla y León. Consejería de Presidencia y Administración Territorial: Valladolid, 1990, p. 8 
B) Dinámica y evolución de la Junta (Presidencia y Consejerías): Destacan las actas y documentos de trabajo en los que se perciben las primeras decisiones en materia presupuestaria, el ejercicio práctico de las primeras competencias transferidas ${ }^{11}$, informes de la presidencia sobre problemas regionales (crisis económica y repercusiones sociales), proyectos y programas de las Consejerias/ Departamentos, nombramientos y ceses(primeras elites administrativas de la Región), asi como preparación de los plenos del Consejo, celebraciones de Villalar, etc.

C) El seguimiento de la tramitación por el Pleno del Consejo General del Proyecto de Estatuto permite una buena aproximación al ideario autonómico y regionalista que subyace en los distintos planteamientos de la UCD., del PSCL-PSOE, de AP(CD) y de los independientes. También los debates sobre el Reglamento de Régimen Interior y sobre materias presupuestarias dan lugar a confrontaciones interesantes.

D) La problemática derivada de la indefinición territorial, la capitalidad, los símbolos y emblemas y las polémicas sobre la declaración del «Día de Villalar» como Fiesta Regional, son los asuntos que más ampliamente concitan las manifestaciones encontradas de fuerzas politicas y entes sociales. Aunque los acuerdos tácitos entre los aparatos de UCD y PSOE, a raíz del famoso Informe Enterria, fueron determinantes en el modelo final de macroregión ${ }^{12}$, en la documentación que nos ocupa y, sobre todo en las recopilaciones de prensa, se perciben claramente las posturas de otras fuerzas políticas de ámbito estatal (CD, PCE), regional (IRCL, ARCL, Comunidad Castellana,PANCAL, PREPAL), local (leonesistas, bercianos, Junta pro-Burgos), y así como de parlamentarios discrepantes (los casos de Modesto Fraile y Carlos GILA) y otras personalidades influyentes. En los momentos decisivos de la incorporación de León a la Comunidad y de las polémicas en Segovia sobre la misma cuestión, abundan los dossiers del Gabinete de Prensa sobre los planteamientos al respecto de las Diputaciones, Ayuntamientos y entidades u organizaciones sociales (sindicatos, Cámara de Comercio, Cámaras Agrarias) de esas provincias.

E) La promoción de una conciencia regional entre los castellano-leoneses: Premios Villalar, certámenes deportivos y culturales, ferias para presentar los productos regionales, etc. Ante todo destaca la documentación

JUNTA DE CASTILLA Y LEON. Competencias y Funciones Transferidas a la Comunidad Autónoma. Consejeria de Presidencia y Administración Territorial: Valladolid, 1986.

12 Orduna Rebollo, E. «El proceso autonómico castellano-leonés y la provincia de León». En: ACTAS X REUNION DE ESTUDIOS REGIONALES II. Junta de Castilla y León: Valladolid, 1985, pp. $831-843$ 


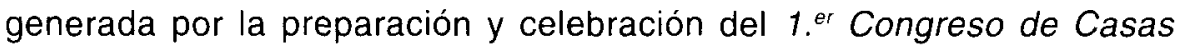
Regionales de Castilla y León, que supuso un paso importante para la proyección de la autonomía sobre los emigrados a otras regiones, (Cataluña, País Vasco...), precisamente quienes más sentían las peculiaridades histórico culturales de Castilla y León.

F) Situación de las infraestructuras y sectores económicos de Castilla y León: Informe EYSER sobre situación socioeconómica, previo a políticas concretas del Consejo General para el desarrollo regional.

G) Relaciones de la Junta con otros administraciones regionales: Generalitat de Cataluña (visitas de Jordi PujoL), Gobierno Vasco, Juntas de Andalucia, Extremadura y Principado de Asturias.

Para el estudio de la etapa Autonómica se dispone de una amplia Guia de información del Fondo Documental de la Junta de Castilla y León ${ }^{13}$, que es un extraordinario instrumento de descripción y de localización de los complejos fondos administrativos generados y/o depositados en diferentes - y sucesivos - órganos del Ejecutivo Regional, hasta diciembre de 1989.

Son muy útiles las orientaciones preliminares sobre las sucesivas reestructuraciones en la composición y distribución de áreas competenciales de la misma Junta y de cada Consejería: remodelación de septiembre de 1984, recomposición con ocasión de la dimisión del Presidente (nov. de 1986), alternancia en el poder, al acceder a la Presidencia el candidato de A.P., Sr. Aznar López, quien reorganiza profundamente la Administración Autonómica (verano de 1987); finalmente, con motivo de los pactos de gobernabilidad entre P.P. y C.D.S., se produjeron también otros cambios y trasvases administrativos (mayo de 1989).

La Guía reseñada particulariza en cada Consejería las competencias, estructura orgánica (desde la Secretaría General y las direcciones generales hasta secciones y negociados, con sus atribuciones), altos cargos, comisiones, etc. Desde el no. 673 hasta el 713 se detallan las funciones de dicho Archivo Central, la tipología de los documentos que recoge de las diferentes consejerias (asuntos político/administrativos, relaciones interinstitucionales, estudios y encuestas sobre problemática autonómica, recopilaciones diarias de la prensa nacional y de la Región, etc), e información sobre las bases de datos disponibles y su uso.

13 Feijoo Casado, A. M., dir. Guía de información del Fondo Documental de la Junta de Castilla y León, Junta de Castilla y León. Consejería de Presidencia y Administración Territorial: Valladolid, 1990. 
En resumen, los fondos catalogados por los servicios archivísticos de la Junta de Castilla y León contienen un importante cúmulo de datos y noticias para reconstruir la historia política e institucional de la Comunidad Autónoma, con especial referencia a las relaciones entre Ejecutivo y Legislativo, trazar la evolución orgánica de la Administración Regional y contemplar las interrelaciones entre los nuevos poderes y las estructuras socioeconómicas o culturales.

Hay que decir que, conforme se racionaliza el diseño de la Autonomía, se cierran los contenciosos territoriales y de la capitalidad; se normaliza el funcionamiento de las instituciones básicas y, por tanto, el componente "politológico" de la documentación se atempera y pasan a predominar los asuntos puramente administrativos o de gestión pública.

\section{ARCHIVO DEL CENTRO REGIONAL DE TELEVISIÓN ESPAÑOLA}

Los planes de descentralización informativa -ante las nuevas realidades regionales - del tercer gobierno Suárez, se plasmaron en Castilla y León con la firma, en junio de 1980, de los protocolos para la instalación del Canal Regional de TVE; pero la permanencia del Ejecutivo Preautonómico en Burgos hasta que - tras las primeras elecciones regionales del 8 de mayo de 1983- la Junta de Consejeros, presidida por el socialista Demetrio Madrid, decidió instalarse en Valladolid, retrasó la ubicación definitiva de los estudios en un lugar estable. Tal provisionalidad resultó dañina para los documentos filmados más antiguos, algunos de los cuales han podido perderse, por no estar almacenados en buenas condiciones, o por la misma caducidad del soporte ${ }^{14}$.

En el edifico central de TVE en Castilla y León, se puede trabajar sobre:

A) El Archivo Antiguo, que posee materiales sonoros y/o gráficos desde octubre de 1982 al mes de abril de 1987, y que ha sido recuperado por técnicos especializados. Está dotado de una estructura alfabética y temática y contiene interesantes asuntos:

- La campaña electoral de las Generales de 1982 en la Región y las primeras elecciones autonómicas del 8-V-83: Presentaciones de candidaturas, emisiones de propaganda, mítines y otros actos, resultados electorales y biografías o comentarios de los líderes políticos.

14 La mayor parte del material se almacena en soportes UMATIC y BETACAM (con código de vueltas), quedando una mínima parte en $1 P$., con código de comienzo, en cintas de 60 y 90 min. 
- Constitución de las Cortes de Castilla y León en Tordesillas y elección de su Presidente y del Primer Presidente Castellano-leonés (21 y 23 de mayo de 1983, respectivamente). Asimismo, las sesiones del legislativo, ruedas de prensa de miembros de la Junta y reuniones de otros órganos colegiados.

- Regionalismo Castellano-leonés y su problemática político administrativa, incluso con relación a otras autonomias.

- Política Interior, Junta de Consejeros, Diputaciones y Ayuntamientos de la Región. Sobre todo ello existen entrevistas a cargos políticos locales, provinciales, regionales o nacionales y a personas representativas de los diversos ámbitos de la sociedad civil.

- Documentales y reportajes diversos sobre asuntos nacionales discutidos y aprobados en el Parlamento o Consejo de Ministros, de especial interés para la Región (política agraria, asuntos sociales, nombramientos, etc).

- Ferias y exposiciones, fiestas (p. eje. Villalar), certámenes con su significado cultural, económico o sociopolítico.

- Conflictividad social: manifestaciones y encierros de matices sindicales, reivindicaciones populares o vecinales, incidentes en las celebraciones de Villalar, protestas ciudadanas variadas.

- Programas y reportajes regionales: minería, artesanía, demografía y recursos humanos, agricultura, ecología, urbanismo, etc.

- Actos de especial relevancia: visitas de SS. MM. Ios Reyes, Ministros, Presidentes de otras Comunidades Autónomas, Mandatarios extranjeros, etc. Momentos en los que se recogen entrevistas con importante carga política. También se incluyen las inauguraciones de curso en las Universidades de la Comunidad Autónoma, entregas de títulos y diplomas (academias militares), etc.

Si resulta ya un tópico el hecho de que los medios de comunicación operan como factor de homogeneización socio-cultural y de delimitación territorial, hemos de destacar la importancia de estos materiales de cronología más temprana, máxime cuando en Castilla y León la prensa escrita local se ha "regionalizado» de manera tardia e incompleta, constituyendo los programas regionales de TV y de las cadenas de radio la referencia informativa básica sobre las instituciones autonómicas para la gran mayoria de los castellano-leoneses ${ }^{15}$.

\footnotetext{
15 El Norte de Castilla es el diario autóctono con un perfil regional más claro; pero su cobertura es insuficiente. En el resto de la prensa priman la información local y provincial, mientras que los
} 
B) El Archivo Moderno (desde mayo de 1987). Esta sometido a tratamiento informático con arreglo al siguiente indice: Materias y asuntos. Personas. Instituciones: regionales, provinciales, locales, partidos, sindicatos y organismos autónomos. Altos Cargos. Programas. Deportes. Lugares.

La valoración de tales materiales exigiría un visionado pormenorizado con el auxilio técnico adecuado; no obstante, a juzgar por los ficheros, los fondos de este Centro Regional de televisión constituyen una fuente de referencia obligada para la historia reciente de Castilla y León.

\section{ARCHIVO DEL GOBIERNO CIVIL DE VALLADOLID}

La opción por el estudio de los fondos documentales de un gobierno civil como el de Valladolid se explica por varias razones: básicamente, porque, al constituir tales organismos la pieza esencial de la administración periférica del Estado, se puede apreciar la proyección de las instituciones y aparatos del mismo en Castilla y León, así como las continuidades y cambios registrados en la modulación del proceso de cambio político, debido a la acción de aquel.

Además, en esa capital se concentran los servicios inherentes a la Delegación del Gobierno en Castilla y León, por lo que se depositan allí fondos de ámbito supraprovincial (esencialmente partes de la Brigada Regional de Información y de los cuartelillos de la Guardia Civil procedentes de León, Salamanca, Zamora y la misma Valladolid).

Por otra parte, esta ciudad ofrecía de entrada marcadas peculiaridades con relación al resto de las provincias de la región, derivadas de una mayor población industrial y de un sector de servicios más moderno.

Desde otro punto de vista, es preciso señalar que las series documentales depositadas en este Archivo registran grandes similitudes con las del Gobierno Civil de Salamanca, ubicadas ya en el Archivo Histórico Provincial de esta ciudad, que estudiamos a continuación.

Los fondos quizá de mayor interés del mismo son una amplísima colección de telex, desde 1975 hasta bien entrados los años ochenta, donde se advierte un constante trasvase de información del Ministerio de

periódicos estatales (que incluyen páginas regionales) mantienen posiciones destacadas (ALMuIÑA, C. "Medios de Comunicación de masas y conciencia regional». En: JIMÉnEz LOZANO, J. y otros. Construir Europa. Castilla y León. Centro de Estudios Ramón Areces: Madrid, 1991, pp. 295-345). 
Gobernación-Interior al Gobierno Civil, y viceversa, así como órdenes e instrucciones que este último recibe de aquel. Se contienen datos sobre los más variados sucesos de la vida local y provincial, preferentemente del nivel político-social, incluyendo los nombramientos y relevos en todo tipo de cargos públicos de la demarcación.

Asimismo, la Secretaría Particular del Gobierno Civil alberga una respetable cantidad de informes de la Dirección General de Política Interior, dirigidos a los gobiernos civiles, donde se marcan las directrices oficiales del Gobierno de la Nación sobre los asuntos más candentes de política general. $Y$, en lógica correspondencia, se conservan los despachos del Gobernador al Director General acerca de problemas locales.

Existe también en dicha Secretaría una interesante encuesta de 1978, confidencial, efectuada por los servicios del mismo Gobierno Civil, sobre corporaciones locales, colegios profesionales, cámaras, sindicatos, partidos, clero, y prensa, etc., en la que se recoge información sobre adscripciones político-ideológicas, situaciones personales, realidades sociales, etc.; hay que destacar el hecho de que la captación de datos se extiende al propio partido entonces en el gobierno y hasta a las élites locales.

Otros dossiers de la Brigada Regional de Información, de los años finales de la década de los setenta, se refieren a la incidencia de los sindicatos entre los funcionarios de la Administración Central y Ayuntamiento vallisoletano. $Y$ con motivo de la incorporación a la AISS del antiguo personal del Movimiento y de los Sindicatos Verticales -1977/78-, hay despachos del Subsecretario de Interior con el Gobernador Civil valorando el proceso.

Tanto en este Gobierno Civil como en los fondos recogidos en el Archivo Histórico Provincial de Salamanca correspondientes a su Gobierno Civil, se halla importante documentación sobre conflictos políti$\cos$ y de orden público en series que ocasionalmente se remontan a los años cuarenta, cincuenta y sesenta: somatenes, licencias de armas y explosivos - con notas reservadas sobre los titulares de los permisos-informes policiales, así como libros de registro de detenidos y confinados gubernativos.

En los archivos de ambos gobiernos civiles de Valladolid y Salamanca, también se encuentran las solicitudes de reunión de todo tipo de asociaciones y entidades, desde las comunidades de vecinos hasta el Consejo de Administración de FASA-RENAULT o las negociaciones de convenios colectivos, por ejemplo, que en la etapa franquista necesitaban aval gubernativo para su celebración. Lo cual, obviamente, permite reconstruir gran parte de las redes sociales de los años setenta en Valladolid. 
Se conserva una colección amplia de partes diarios de orden público —de 1975 a los años ochenta — que reseña puntualmente las actividades sindicales y políticas, urbanas y rurales, en toda la provincia. En estas mismas series de la Guardia Civil y Jefatura Superior de Policia, se encuentra abundante material propagandístico - hojas volanderas, panfletos, pegatinas, carteles, pancartas y prensa clandestina-, que ocasionalmente era reseñado por los mencionados servicios policiales ${ }^{16}$. Hay también órdenes y circulares del gobernador civil a la policía y a la guardia civil.

En los gobiernos civiles se centralizaba múltiple documentación referida a los procesos electorales: de los Procuradores de las Cortes franquistas, y de los abiertos tras el referéndum para la Ley de Reforma Política. Incluso, se recopilaban datos de las elecciones sindicales.

Las relaciones nominales e informes sobre alcaldes depositadas en el Archivo de referencia, pueden medir el grado de continuidad del personal político local a lo largo de la Transición; existen además las preceptivas comunicaciones de los acuerdos plenarios municipales anteriores a las elecciones locales de 1979.

Como organismo periférico de la Administración Central, el gobierno civil de Valladolid puede, a través de su archivo, aportar datos complementarios sobre el grado de estabilidad social durante la Transición, ya que tiene fondos relativos a las políticas sociales del periodo.

Finalmente, se conservan amplios dossiers de prensa elaborados por el gabinete ad hoc, entre 1976 y 1983. Y las Memorias oficiales anuales del Gobierno Civil —1971,1973 a 1977 y 1978 a 1989—, con datos referidos a plantilla y actividades, evolución económico-laboral de la provincia, estado general de la misma, problemática de la Universidad y movimientos ciudadanos y agrarios.

En conclusión, este apartado sobre el Gobierno Civil de Valladolid muestra, a nuestro juicio, el peso de los aparatos estatales durante la etapa de la Transición; las alteraciones más apreciables se deben fundamentalmente a modificaciones en las lineas de la política nacional, y no tanto a reformas internas del entramado burocrático, sobre todo por lo que a las fuerzas de orden público se refiere. Además, en el caso de Valladolid, se trata de controlar y responder a una mayor fortaleza y articulación de las fuerzas

16 Los apuntes inciden sobre la existencia de símbolos anarquistas (sic), insultos al Rey, a la Policia y FF. AA. y referencias a la ultraderecha, e identifican autores (Jefatura Superior de Policia. Asunto: Actividades Estudiantiles, fechas: 24 de enero y 3 de febrero de 1977. Reg.1639). 
democráticas opositoras, aunque nunca llegan estas a amenazar seriamente la estabilidad de la situación provincial.

\section{ARCHIVO HISTÓRICO PROVINCIAL DE SALAMANCA}

Hemos elegido este Archivo por encontrase en él abundante material documental y bibliográfico, generado por diversos organismos e instituciones de la etapa final del franquismo y comienzos de la Transición. Los datos que aportamos están basados en la información que generosamente ha brindado su directora, Dñ ${ }^{\text {a }}$. Asunción Sáenz, quién ha elaborado para nosotros un amplio resumen de fondos.

Destacaremos la documentación concerniente a la A/SS, a la Secretaria General del Movimiento y al Gobierno Civil-que hemos referenciado someramente al hablar del de Valladolid-; además, existe una sección bibliográfica y propagandística, constituída a partir de diversos organismos periféricos del Estado en Salamanca. Veamos:

- En la parte correspondiente a la AISS, se localizan los documentos de los Sindicatos Verticales entre 1970 y 1977; por ejemplo: Congresos, Consejos Económico-Social y de Trabajadores, Convenios Colectivos, Memorias de Actividades y censos o actas de procesos electorales en las Hermandades Agrarias. Se añaden otros sobre la vida interna de los distintos sindicatos de rama o sector, así como la política de promoción social desarrolla desde la Organización Sindical.

- Las pertenencias de la Secretaría General del Movimiento se distribuyen en: Frente de Juventudes, con libros de registros y actas, movimientos de mandos y afiliados (1970-1978); Sección Femenina, con lo referente a Servicio Social, residencias, escuelas y albergues, así como circulares, correspondencia con la directiva nacional y listados de afiliadas.

- Del amplio fondo bibliográfico y hemerográfico, de temática político/ ideológica oficialista, destacan: Boletines del Movimiento (1966-1977), del Centro de Documentación de la Comisaría para el SEU, de la Delegación Nacional del Frente de Juventudes (1956-1977), de la Dirección General de la Juventud (1978-79) y de la Politica Cultural del Instituto de Estudios Políticos (1973). Entre las publicaciones periódicas se encuentran: Revista de Estudios Politicos (1942-1977), Temas españoles (19521971), Teresa (1954-1970) y Consigna (1941-1977). Y finalmente, Informes del Gabinete Técnico del Consejo Económico Sindical Nacional (1960-1973). 
En definitiva, se puede apreciar el valor de estos fondos para el estudio de la dinámica interna de las instituciones más características de la Dictadura, cuando se avecinaba el cambio político.

\section{ARCHIVOS LOCALES: DIPUTACIÓN Y AYUNTAMIENTO DE LEÓN}

Cuando la Comunidad Castellano-leonesa accede a la autonomía hereda varios contenciosos:

- Uno, histórico-ideológico. Para cierta derecha continuista, Castilla (la Madre que parió España) había sido políticamente descuartizada en cinco Comunidades ${ }^{17}$.

- Otro, relativo a la delimitación y articulación de su territorialidad: el contencioso leonés ${ }^{18}$ habia culminado el 13 de enero de 1983, cuando la Diputación Provincial votó mayoritariamente dejar sin efecto el acuerdo de adhesión al proceso autonómico conjunto (abril de 1980); por esos mismos dias arreciaban las manifestaciones en Burgos para reivindicar la capitalidad castellana y unos meses antes se habían solicitado, desde esta última, subvenciones a la Junta para apoyar una campaña en favor del mantenimiento en Castilla del Condado de Treviño; finalmente, Segovia, cuyos municipios se habian mostrado mayoritariamente contrarios a la iniciativa autonómica ${ }^{19}$, hubo de ser incorporada mediante una vía excepcional: La

17 La Gaceta Regional. Salamanca, 17 de julio de 1982, p. 16 y El Adelanto, Salamanca, 17 de agosto de 1982, p. 1. El historiador Anselmo CARRETERo se lamentó: "Castilla ha sido fraccionada en cinco pedazos. Uno de ellos (Burgos, Soria, Segovia y Avila) ha sido agregado al País Leonés para formar arbitrariamente una nueva e hibrida región político-administrativa llamada Castilla y León, que no es Castilla, porque sólo incluye una parte minoritaria de esta, ni es León, porque contiene cuatro provincias que no son leonesas. Otro pedazo (Guadalajara y Cuenca) ha sido añadido al País Toledano y a la provincia de Albacete para crear otro hibrido engendro, denominado Castilla-La Mancha ... El tercer pedazo arrancado de Castilla (la Montaña cantábrica, Montaña Baja de Burgos o Costa de la Mar de Castilla, hasta ayer llamado Santander) puesto en el dilema de quedarse incluido en el conglomerado Castellano-leonés ... ha optado por la autonomía uniprovincial. Lo mismo ha ocurrido en La Rioja (cuarto trozo) Por último, tampoco figura el nombre castellano en la Provincia autónoma de Madrid..." ("La cuestión nacional en Castilla y León». En: HeRnÁndez, F. y MeRCAdo, F.: Estructuras sociales y cuestión nacional en España. Barcelona: Ariel, 1986 pp. 313-314).

18 Cabañas Vazouez, C. Esto es el País Leonés. Ed. Amelia Boudet: Barcelona, 1988. Diez Llamas, J. D. La Identidad Leonesa. Diputación Provincial: León, 1992, pp. 183- 242.

19 Hubo una fuerte polémica porque el Ayuntamiento de Cuellar alteró su postura reequilibrando las posiciones en favor de la adhesión a Castilla y León, frente a los que deseaban una Región Central (epicentro en Madrid) o la Autonomia uniprovincial (IGLESIAS CARREÑo, F.: "La sentencia de Cuellar y la autonomía constitucional de los municipios". ANUARIO 1990. Instituto de Estudios Zamoranos Florian de Ocampo: Zamora, 1991, pp. 432- 445) 
Ley Orgánica 5/1983 de 1 de marzo, en virtud del art. 144.c de la Constitución («razones de interés nacional»). Hasta tiempo después de haberse pronunciado el Tribunal Constitucional confirmando la integración de León y Segovia (28-IX y 8-XI de 1984, respectivamente), no se atemperaron los ánimos localistas.

¿Por qué hemos elegido como tipos de archivos locales el del Ayuntamiento y la Diputación de León? Sencillamente, porque en León fue donde con más fuerza cuajó un sentimiento favorable a la autonomía uniprovincial. Hasta tal punto que se llegaron a utilizar símbolos nuevos en las instituciones locales.

Nuestra indagación en el Archivo Municipal leonés nos permite referir los siguientes fondos:

- Libros de Actas de los Plenos, números 35 a 42, que abarcan el período de noviembre de 1967 al mes de abril de 1980. Destacan los temas de urbanismo, personal, educación y cultura (se colabora con otras entidades en la transformación del Colegio universitario, asuntos sociales (beneficencia, pensiones...), protocolo, etc. Hacia comienzos de los años setenta se observan ciertas pugnas entre los concejales, al renovarse la Diputación Provincial. Con motivo de las primeras elecciones municipales de abril del 79, se produce, igual que en toda España, la remoción de las élites políticas locales que, en nuestro caso, supone el duradero mandato del Alcalde Juán Morano Masa, exponente fundamental del movimiento leonesista.

- Actas de la Comisión Permanente (años 1975-79).Pueden utilizarse para rastrear el movimiento vecinal y asociativo y seguir la continuidad de la vida interna de la institución durante la Transición y la fase inicial del proceso autonómico.

- Libro de Decretos de la Alcaldía (1976), que contiene las resoluciones que dicta la Autoridad Municipal en ejecución de acuerdos plenarios (Art. 12 del entonces vigente Reglamento de Organización, Funcionamiento y Régimen Juridico de las Corporaciones Locales).

- Boletín de Información Municipal (después llamado Concejo). Su número 1 apareció a comienzos de 1971. Es trimestral e incluye: Sintesis de los acuerdos de los Plenos y de la Comisión Permanente, decretos del Alcalde-Presidente, datos y estadísticas de los movimientos poblacionales, notas necrológicas sobre personalidades fallecidas (leoneses ilustres), asistencia social,intervención, etc. Es un buen baremo para medir la proyección que trata de ejercer la institución sobre los ciudadanos.

En el Archivo de la Diputación Provincial se conservan: 
- Actas de los Plenos (y sus correspondientes borradores), de las que consideramos más conveniente revisar las posteriores a 1979, cuando las elecciones locales renovaron la vida de la Corporación. Incluyen los presupuestos y sistemas de recaudación contributiva, planes especiales comarcales (Riaño, los Ancares...), obras de infraestructura en los municipios, centros asistenciales, etc.

El debate sobre la autonomía regional se hace presente fundamentalmente cuando el 1 de junio de 1979 se crea una Comisión Gestora de la Autonomía Leonesa, con participación de todos los partidos del ámbito estatal (UCD,PSOE,AP y PCE), asi como el 13 de enero de 1983, al aprobarse la moción del diputado de AP, José $\mathrm{M}^{a}$. Suárez sobre la iniciativa para la constitución del Ente Autonómico Leonés.

Cuando acceden a la Presidencia los socialistas, en junio de 1983, el contencioso del uniprovincialismo se invierte a favor del modelo actual, aunque el problema sigue latente ${ }^{20}$.

- También se conserva la $1^{a}$ Encuesta Institucional "León ante la Autonomia"(año 79) que contiene las preferencias de la población provincial sobre la demarcación territorial y el grado de concienciación leonesista. Se añaden a ella los acuerdos de entidades públicas que motivan la misma, la metodología empleada y la evaluación final de la muestra.

- Las Memorias de Actividades no tenían una periodicidad determina, porque las elaboraban los diferentes Presidentes al finalizar sus mandatos, o al abandonar el cargo. Por ejemplo, la correspondiente al período 19791982 coincide con la etapa del gobierno ucedista de Julio César Rodrigo de Santiago y contiene el siguiente indice: Características de la Provincia (territorio, población e infraestructuras), Organización, funcionamiento y actividades generales de la Diputación, Servicios de la competencia provincial (actuaciones), Hacienda y Servicios económico-administrativos.

\footnotetext{
20 Pérez Ruiz, A. "Criterios". TIERRAS DE LEON, N57, diciembre de 1984, pp. III -VI.

Ultimamente, el pleno de la Diputación leonesa aprobó -por dos votos a favor de la Unión del Pueblo Leonés y del CDS-, con la abstención de los grupos mayoritarios del PSCL-PSOE y $A P$, una moción solicitando un referendum sobre la integración -o no- de León en esta Comunidad Autónoma "compuesta". (El Mundo, suplemento de Castilla y León, 24 de diciembre de 1994, p. 1. ABC, 24 y 30 de diciembre de 1994, respectivamente: pp. 55 y 117) Asimismo, en el Pleno del Ayuntamiento de León, dicha moción obtuvo el respaldo 11 concejales del PP y los 3 de UPL, votaron en contra 7 concejales de PSOE y 1 del PP, absteniéndose 2 ediles del PSOE (Presidente y Vicepresidente de la Diputación Provincial), otro del PP y el único de IU. Naturalmente, la crisis en los dos partidos mayoritarios en Castilla y León - PP gobernante y PSCL-PSOE, oposición-, pudiera ser importante y reabrirse el viejo contencioso de ta territorialidad. (E/ Mundo, supl. regional, 2 de enero de 1995, pp. 1-3. ABC, 2 de enero de 1995, p.55. El Pais, supl. ciudades, 2 de enero 1995, p.2)
} 
- Fondos hemerográficos, que son relativamente ricos, si tenemos en cuenta lo efímero de muchas publicaciones locales al final del franquismo y la Transición. Encontramos:

- LA TARDE RADICAL. Diario vespertino del País Leonés. Se conservan los cinco números editados, del 11 al 15 de diciembre de 1979. Sigue una línea de izquierda próxima a la Federación Socialista Leonesa (PSOE), que por entonces se mostraba todavía bastante reacia a la Preautonomía castellano-leonesa. En sus secciones habituales, aparte de la información política general y local, se trataban con detenimiento el tema regional, los movimientos vecinales y sociales, mostrándose abierto a la opinión de los lectores.

- LA CANDAMIA. Gaceta de León y Provincia. Parece bimensual, al menos en sus comienzos: el número 1 es del 15 a 31 de agosto de 1982. Incluye cuestiones artísticas, folklore y cultura popular.

- GENERACIÓN-81. Gaceta Leonesa, cuyo interés se reduce a curiosidades de la vida local.

- LEÓN QUINCENAL. Periódico bimensual de información sociopolítica y cultural, de orientación independiente y radical.

- CERANDA. Semanario independiente de las comarcas leonesas. Apareció el 28 de septiembre de 1978 y su último número (el 57), corresponde a los días 7-13 de marzo de 1980. El proyecto era ambicioso y su preparación fue relativamente minuciosa. Según el profesor Miguel Cordero, uno de sus inspiradores, ante el carácter casi "monocorde" de los medios de comunicación leoneses, «a partir de octubre de 1977 se desarrollaron varias reuniones de personas independientes, liberales y progresistas con miembros de la izquierda (...) y con la participación del grupo berciano, al que se asociaron también gentes de Valdeorras" ${ }^{21}$, para la constitución del citado medio periodístico.

- Entre las firmas fundacionales se encontraban, desde el senador real Justino Azcárate hasta antiguos miembros de la Junta Democrática; se autoconsideraba "no neutro" y su línea ideológica pensamos que se aproximaba a la izquierda parlamentaria.

Diversos problemas (el sector berciano, intentos de manipulación de algún partido, las erupciones de voluntarismo, la pésima organización y otros males), acabaron en menos de dos años con esta interesante experiencia,

21 Cordero del Campillo, M. Crónica de un compromiso. Los años de la transición política en León. Santiago Garcia: León, 1988, pp. 332-333. 
que constituyó un revulsivo para los círculos más conservadores de la provincia, agrupados entonces en torno al “Diario de León».

- TIERRAS DE LEÓN es un Boletín editado por el Gabinete de Prensa de la Diputación Provincial, que contiene abundante información histórica, cultural, literaria, artística, biográfica y bibliográfica, sobre temas leoneses, con abundante material gráfico correspondiente a los meses finales del 79 y comienzos de los años ochenta. Interesa en particular la sección llamada "De la vida Provincial", con actos diversos del Presidente y diputados, o la denominada "Criterios», donde se expresan opiniones políticas "oficiosas" emanadas del entorno de la presidencia de la Institución.

- LA YORBA, editado a ciclostil, de periodicidad irregular, de tendencia cristiano-radical y de fuerte contenido didáctico. Es un órgano de expresión dirigido a los agricultores próximos a lo que con el tiempo fue la Unión de Campesinos Leoneses y se conserva algún número a partir de 1975.

- LEÓN. Revista de la Casa de León y órgano del Instituto de Estudios Leoneses, contiene información sobre historia, cultura y una amplia miscélanea. Sus colaboradores son figuras bastante conocidas en la vida local, y hasta nacional, con fuertes vínculos con esta tierra.

- Fondos diversos: Listado de los ayuntamientos de la Provincia y orientación "política» de los mismos (Secretaría General), correspondiente a los años 1976-77; biografías de diversas personalidades públicas de la provincia; nombramientos de Presidente y Comisiones Gestoras en las Entidades Locales Menores.

Finalmente, se conserva documentación dispersa relativa al Consejo General de Castilla y León (años 1980-83), como actas de reuniones de la Junta, Anteproyectos de Estatuto, Reglamento de Régimen Interno, así como documentación emanada de la Secretaría General del mismo (actividades, presupuestos, líneas generales de actuación política...).

Merece citarse de manera muy especial el fondo fotográfico de CESAR, con abundante material referido a los múltiples aspectos de la vida provincial.

\section{ARCHIVO DEL PARTIDO SOCIALISTA OBRERO ESPAÑOL}

El proceso autonómico, excepto en los casos vasco y catalán, donde existían partidos nacionalistas fuertes, se fue perfilando a través de una dialéctica fluida de confrontaciones y acuerdos entre los dos partidos mayoritarios a nivel estatal: UCD y PSOE, que ademas ocupaban gran parte de los puestos en los entes preautonómicos. 
En el caso concreto de Castilla y León, durante los años de la transición, estas dos formaciones sintonizaron mejor con los sectores urbanos medios - ahora mayoritarios ante la pérdida de peso del campesinado tradicional por la sangría emigratoria de los $60-$ y en las elecciones generales de junio de 1977, marzo de 1979 y locales de mayo de 1979, ambas se repartieron, con predominio de UCD, una muy buena parte de los cargos institucionales en disputa, quedando el resto de las fuerzas políticas en situación prácticamente marginal.

En proporción a tales resultados, el Consejo General de Castilla y León (órgano preautonómico) quedó compuesto por una gran mayoría de parlamentarios nacionales y diputados provinciales de Ia UCD y una pequeña y activa minoría del PSCL- PSOE, ostentando una representación testimonial AP (CD) y los independientes. Bien es cierto que las entidades y grupos regionalistas (ARCL, IRCL, Comunidad Castellana, GAL, etc.), trataron de influir sobre el Pleno del Consejo y la Junta de Consejeros; sin embargo, para que estos hubieran condicionado decisivamente la política autonómica del Gobierno de la Nación, se habría necesitado una mayor implantación de la conciencia de diferenciación regional y un más amplio respaldo popular a un modelo distinto de autonomia.

Por tanto, el proceso de transición y la marcha de la Preautonomía en esta Región registran una gran similitud con el marco general consensuado por las fuerzas políticas de ámbito estatal.

Desde este punto de vista, para el estudio del cambio político y la institucionalización autónoma resultan de interés preferente los fondos documentales de las organizaciones regionales de UCD y del PSCL-PSOE, ya que la articulación de AP fue más tardía y el PCE mantenía posiciones próximas a entidades como el Instituto Regional Castellano Leonés, objeto más adelante de nuestra atención.

Hemos optado por trabajar sobre el Archivo de la Sede Regional del PSCL-PSOE, en Valladolid, y el de su Grupo Parlamentario, por ser los socialistas la primera fuerza política que se organizó regionalmente ${ }^{22}$ y porque los fondos de la extinta UCD están dispersos y, preferentemente, en manos privadas.

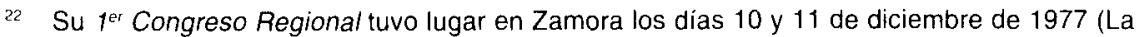
Federación Socialista Leonesa no se incorporó hasta el 1 I $^{\text {er }}$ Congreso Regional de Valladolid, 19 20 de diciembre de 1981) Semanas antes ya se habian reunido sus Diputados y Senadores (Villalar, 3 de julio de 1977) para reclamar el Régimen Preautonómico. La pequeña minoria socialista en los órganos preautonómicos se mostró muy activa frente a la gran mayoría de UCD: El Prof. QuiJano Gonzalez y otros militantes redactaron para el Pleno del Consejo General de Soria (25 de enero de 1980) un Borrador de Proyecto de Estatuto que se asemejará bastante al texto 
Los fondos documentales que pueden encontrarse comprenden:

1) Congresos Regionales, ordinarios y extraordinarios: Convocatoria, preparación, listados de delegados, ponencias, actas y resoluciones. También se puede encontrar documentación sobre las fases provinciales previas a la celebración de los congresos regionales.

2) Comisión Ejecutiva y Comité Regional (1977-1994): Actas de reuniones, memorias de gestión por secretarias, planes de trabajo y organización de las mismas. Asimismo, se conservan algunos dossiers de la correspondencia cruzada entre Comisión Ejecutiva Regional-Grupo Parlamentario-Junta de Consejeros (1983-1987)-Organos FederalesFederaciones Regionales-Agrupaciones locales.

Integradas en ambos organismos funcionan Comisiones de trabajo diversas, sobre las que se conserva documentación muy dispersa sobre su funcionamiento, cometidos y relaciones intraorgánicas

Igualmente, existen fondos sobre las diversas campañas electorales del PSCL-PSOE, en sus distintos ámbitos geográficos de actuación. Y también se encuentran comunicados y dossieres de prensa sobre distintos problemas nacionales, regionales y locales.

Finalmente, en la sede regional del PSCL-PSOE se encuentran 11 números (enero 1985-abril 1987) de la revista TEMAS de Castilla y León, editada por la Oficina del Portavoz de la Junta.

3) Agrupaciones provinciales: fundamentalmente correspondencia entre estas y los órganos ejecutivos regionales.

4) Grupo Parlamentario; distribuye sus fondos entre los locales que tiene asignados en el Castillo de Fuensaldaña y la sede oficial del partido. Aparece la típica documentación generada por una minoría parlamentaria.

En síntesis, creemos que los archivos de esta formación política arrojan bastante luz sobre los procesos que se vivieron en Castilla y León durante la transición e implantación del sistema autonómico.

vigente. En otros Plenos (Palencia, 12 de julio de 1980, Salamanca, 14 de enero y Monzón 4 de marzo de 1983) presenta programas de gobierno y candidato alternativo (el entonces Secretario General, el abogado vallisoletano, Juan Antonio Arévalo) a la Presidencia del Consejo de Castilla y León. Fruto de esa buena labor y el efecto arrastre de la victoria socialista en las elecciones generales del 28 de octubre de 1982 fué su sorprendente mayoria relativa en las primeras elecciones autonómicas (mayo de 1983), cuando accedió a la Presidencia de la Junta, el candidato socialista Demetrio Madrid López. 


\section{PARTIDO REGIONALISTA DEL PAIS LEONÉS (PREPAL)}

En la España de la Transición, la interpretación de las fuerzas de izquierda acerca de que los nacionalismos periféricos constituian un componente clave en el proceso democratizador -aunque sólo fuese como reacción frente al agudo centralismo de la dictadura, o para sumar fuerzas al proyecto rupturista - hizo que la cuestión nacional-regional gravitase decisivamente sobre todo el proceso de cambio; es ya un tópico reconocer que "el atrevido paso político de la UCD al generalizar el proceso autonómico al conjunto de España» ${ }^{23}$, dio lugar a la convivencia de «regionesinstitución", claramente diferenciables, junto a Comunidades Autónomas de dificil justificación o discutible necesidad.

En Castilla y León, a la indefinición territorial, se sumó un grado débil de autoidentificación colectiva. Las organizaciones sociopolíticas de variado matiz regionalista, que aspiraban a representar las peculiaridades autóctonas,encontraron la competencia de los partidos de ámbito estatal y de los movimientos inspirados en sentimientos provincialistas y hasta comarcalistas.

De entre todos estas organizaciones, hemos elegido - con criterio discutible, sin duda - al Partido Regionalista del País Leonés (PREPAL).

De ideología humanista, socialdemócrata e interclasista, considera que el proceso preautonómico Castellano-leonés fue improvisado, irregular y anticonstitucional. Defiende uel irrenunciable derecho a la autonomía del territorio del antiguo Reino de León, poseedor de una cultura milenaria y económicamente diferente de los otros pueblos que forman España" (Declaración programática, punto F) y trata de afianzarse en las tres provincias occidentales del histórico Reino, mientras que los otros movimientos leonesistas tienen como epicentro la antigua capital del mismo.

A través de su Archivo, depositado en el domicilio del Secretario General, Don. Francisco Iglesias Carreño, en Zamora, puede reconstruirse su historia.

Se conservan manifiestos, articulos periodisticos ${ }^{24}$, boletines (los Cuadernos del País Leonés, años 1981 y 1982) y notas manuscritas sobre contactos con otros grupos de temprana orientación regionalista.

23 Blas Guerrero A. de. Sobre el Nacionalismo Español. Centro de Estudios Constitucionales: Madrid, 1989, p. 114. YSAS, P. "Democracia y Autonomia en la transición española". AYER, N ${ }^{\circ} 15$, 1994, pp. 77- 108 .

24 Iglesias Caraeño, F."Artículos-86", en ANUARIO 1988 del Inst. de Est. Zamoranos Florian DE Ocampo, pp. 295-344. Diego NúNEZ, M. de. «Pais Leonés y Constitución Española». El Adelanto, 16 de diciembre de 1994, p. 22. 
Asimismo, existe documentación sobre su vida orgánica: Actas de las nueve Asambleas Generales (equivalentes a los congresos de otras formaciones), celebradas hasta el momento; el libro de altas y bajas de sus militantes (útil para el perfil sociológico e implantación geográfica del partido); resoluciones y circulares; correspondencia con otros grupos leonesistas y castellanistas; candidaturas presentadas en los distintos procesos electorales; una colección de publicística (panfletos, heráldica leonesa, manifiestos, bocetos y carteles); finalmente, un útil Libro de Registro de entradas y salidas de correspondencia y el Acta Notarial de su constitución.

En esta documentación, se pueden apreciar los momentos de más proyección pública de este partido: convocatorias electorales; presentación del nuevo partido en los primeros meses de 1981; celebración del VIII Centenario de las Cortes Leonesas, en 1988; llamamientos leonesistas de su iniciativa (los que hace anualmente festejando el «Día del País Leonés"), o de entes que funda e integra (Grupo Regionalista Salmantino, Juventudes Leonesistas, Consejo General de la Región Leonesa); manifestaciones conjuntas con otras fuerzas políticas, en León, los años 1983, 1984 y 1985, contra la incorporación de esta provincia a la Comunidad Autónoma de Castilla y León.

De tales actividades y del problema de la conformación de la autonomía actual, tal como la ve el PREPAL, este archivo conserva material video-gráfico, articulos periodísticos, alguna grabación radiofónica, así como cartas de protesta y sensibilización a personalidades y organismos del Estado (Rey, Presidente del Gobierno y Tribunal Constitucional).

Resumiendo, creemos que la trayectoria de este grupo intraregionalista podría confirmar la dificultad del arraigo y consolidación de iniciativas políticas, territorialmente fraccionales, de la Comunidad Autónoma Castellano-leonesa. Hasta el momento, sólo algunos dirigentes populistas han logrado capitalizar -en los Ayuntamientos de León y Burgos-el sentimiento localista frente a la actual macroregión funcional. Posiblemente, la falta de una burguesia autóctona poderosa y la ya citada carencia de autoconciencia regional sean los obstáculos mayores para el arraigo de fuertes partidos regionalistas en lo que hoy es Castilla y León.

$Y$ es que, difícilmente puede sentirse "región» un territorio poco ahormado sobre el que, en el pasado, ha gravitado la centralidad del Estado español, con sus clases agrarias tradicionales en regresión y unos grupos urbanos intermedios de difusa identidad. 


\section{ARCHIVOS SINDICALES: ARCHIVO HISTÓRICO DE LA UNIÓN REGIONAL DE COMISIONES OBRERAS DE CASTILLA Y LEÓN}

Aunque la dictadura franquista no cerró su ciclo hasta la muerte natural de su fundador y las presiones de la oposición se revelaron insuficientes para terminar con el régimen, seria poco honesto y escasamente ajustado a la realidad de los hechos históricos, negar la relevancia de la lucha que las fuerzas antifranquistas llevaron a cabo, en medio de innumerables dificultades. Tras la muerte de Franco, la oposición democrática contribuyó de forma destacada a bloquear los procesos pseudorreformistas del gobierno de Arias Navarro, si bien no consiguió dirigir el proceso de Transición a la democracia, a la que, sin embargo, empujo con su presión.

Los sindicatos eran, por lo demás, un gran poder social; se habian convertido, en especial CC.OO., en la base más amplia y firme con la que la oposición antifranquista contaba para deslegitimar el régimen dictatorial, impulsarle hacia su crisis y aspirar a imponer una ruptura con él. Desde esta perspectiva, parece evidente la necesidad del estudio del movimiento sindical en el momento histórico de la crisis del franquismo y en los primeros años de la democracia.

En las provincias que actualmente configuran la Comunidad Autónoma de Castilla y León, el movimiento sindical, sin embargo, tuvo una presencia no excesivamente fuerte, dadas las condiciones de desarrollo económico y social en las que se desenvolvía la región ${ }^{25}$. La debilidad del movimiento sindical afectó a la capacidad de la oposición democrática para articular en estas provincias un frente rupturista de relieve y posibilitó a las élites políticas del antiguo régimen una mayor capacidad de movimientos para dirigir el proceso de la Transición.

El estudio del movimiento sindical castellano-leonés tiene que enfrentarse a la pérdida de una parte considerable de la documentación generada en su propio desarrollo. Dejando a un lado las fuentes depositadas en archivos situados fuera de la región, dentro de ésta puede encontrarse documentación dispersa en muy distinta localización. Un recorrido por las sedes sociales de los diferentes sindicatos suele deparar el hallazgo de algún documento, en la mayor parte de los casos, semiolvidado. En ocasiones, viejos militantes poseen documentación que, aunque con ciertas

25 Carantoña Alvarez, F. y Pozo, J.C. del: "Comisiones Obreras en Castilla y León: De la huelga minera de 1962 al Primer Congreso Regional (1978)". En: Rulz, D., dir. Historia de Comisiones Obreras (1958-1988). Siglo XXI: Madrid, 1993, pp. 345- 362. 
reticencias, generalmente puede ser consultada por los investigadores. Algunas empresas, fundamentalmente las de mayor tamaño, y varios abogados laboralistas, conservan documentación que puede ser de gran utilidad para el investigador. Asimismo, en los gobiernos civiles y, en su caso, en los Archivos Histórico-Provinciales, se halla, a veces, documentación dispersa sobre esta temática.

En medio de esta situación, no excesivamente prometedora para el historiador del movimiento sindical, es preciso resaltar el esfuerzo de recogida de fuentes y posterior organización llevado a cabo desde el ámbito de CC.OO. El Archivo Histórico de la Unión Regional de CC.OO. de Castilla y León, ubicado en Valladolid, y dirigido por Juan Carlos del Pozo, está integrado en la Fundación de Investigación y Documentación de la Unión Regional de CC.OO. de Castilla y León, nacida en enero de 1990.

Los fondos de este archivo, documentación interna generada por el movimiento obrero de la región, en particular por CC.OO., y publicaciones periódicas, casi todos ellos referidos a los años setenta, han sido donados por distintas organizaciones, destacados militantes y abogados laboralistas, en su mayoria de CC.OO.

Aunque puede encontrarse alguna documentación de casi todas las provincias de Castilla y León, destaca la concerniente a Valladolid, referida a FASA, SAVA, RENFE, MICHELIN, MAGGI y a algunos bancos de la ciudad.

En la actualidad están catalogados e informatizados unos mil documentos y la mayor parte de las publicaciones periódicas. En el catálogo del Fondo de José María Alonso Franch, Abogado Laboralista (19661968), el investigador puede detectar expedientes relacionados con el mundo laboral y con el Tribunal de Orden Público, referidos sobre todo a militantes comunistas y de CC.OO., así como aspectos variados que tienen que ver con las condiciones de vida y de trabajo de diversos colectivos de asalariados.

El catálogo del Fondo de Gonzalo González Alvarez, 1968-1978, líder de CC.OO. del ramo de la construcción y el catálogo del Fondo de Javier Fernández, militante leonés de CC.OO. en RENFE en los años setenta y actualmente Secretario General de la Unión Regional de CC.OO. de Castilla y León, recogen básicamente documentación centrada en la propaganda sindical y política de los setenta y algunos textos internos de CC.OO.

Por último, el catálogo del Fondo del Sindicato de Banca, Bolsa y Ahorro (1970-1977) presenta documentación sobre convenios colectivos 
del sector, condiciones de trabajo, incoación de expedientes sindicales a representantes de los trabajadores, etc.

\section{ARCHIVO PARTICULAR DEL PROF. JOSÉ LUIS MARTIN RODRIGUEZ (IRC-L)}

El Instituto Regional Castellano-Leonés aparece como Sociedad Anónima -esquivando los estrechos márgenes de la normativa asociaciacionista vigente- en los inicios de la Transición (marzo de 1976), con dos finalidades muy claras: Elaboración de análisis y propuestas de solución al retraso económico de la región natural que comprende la Cuenca del Duero (Art. 4 del Estuto Social), y construcción de un pensamiento regionalista reivindicativo, que denuncia la «utilización" de Castilla por el centralismo político y el desarrollo capitalista, vaciándola de hombres y empobreciendola. Más que de un nuevo regeneracionismo, el IRC-L. trata esencialmente de adecuar su lenguaje al "victimismo" de los nacionalismos periféricos, señalando las diferencias entre Castilla y León y el conjunto nacional/estatal. Sus Estatutos y Reglamentos establecen una organización flexible y descentralizada, teniendo como elemento básico los grupos de trabajo provinciales que se coordinaban regionalmente, a la cabeza de los cuales figuraban los Presidentes de las estructuras locales.

La vida interna de la entidad, queda refleja en este archivo: estados de cuentas; correspondencia con socios y simpatizantes, personalidades políticas y del mundo de la cultura o enseñanza, partidos, asociaciones regionales, movimientos sociales y sindicatos agrarios; convocatorias de reuniones plenarias, comisiones, etc.

Su proyección externa es notoria y del máximo interés, como se observa en la amplia colección de escritos enviados a la prensa salmantina y regional acerca de temática municipal, socioeconómica, manifiestos sobre la situación política en los diversos momentos de la Transición -en sintonia apreciable con la Junta y Coordinación Democráticas-, llamamientos a las Jornadas reivindicativo/festivas de Villalar (convocada la primera sin autorización y en solitario por esta organización, el 24 de abril de 1976).

Como medio de articulación de una conciencia regional, el IRC-L realizó ciclos de conferencias, festivales folklóricos, planeó campañas de divulgación de su ideario, certámenes o muestras de artistas plásticos, y las llamadas "andanzas» excursionistas dirigidas al conocimiento geohistórico de las comarcas castellano-leonesas (1976-79). Existe también un fondo sobre diversos proyectos editoriales, Congresos de Estudios de Castilla y 
León y lanzamiento de una revista titulada: "Reporter de Castilla y León» (1977).

El carácter aglutinador de un regionalismo de izquierdas se percibe en la variada documentación relativa a problemas medioambientales, múltiples iniciativas contra la fábrica de combustibles nucleares de Juzbado (marchas, manifestaciones, denuncias, debates) entre finales de 1976 y 1979, y correspondencia con entidades como AEORMA, ADELPHA o Centro Castellano de Estudios Ambientales. También apoya movimientos alternativos de enseñantes, como las Escuelas de Verano.

Debido a la configuración ideológico/política de sus miembros y a esa orientación de la entidad en cuanto tal, se encuentran en este fondo, documentos teóricos, análisis programáticos y electorales, estatutos y manifiestos de las organizaciones locales y regionales del PCE, Partido Castellano-Leonés, Federación Social Independiente (de Jesús Sancho Rof), Movimiento Socialista, PSP, Federación Popular Demócrata, MC, Convención Republicana, ARDE, Asamblea de Castilla y León e, incluso de UCD (años 1976 a 1980). Hay números sueltos de publicaciones regionales o locales: Concejo Abierto, El Pendón, El Concejo, Nuestra Castilla, Llama Comunera y Tierra (1975-1980).

Especialmente rica es la parte dedicada al Grupo Independiente de Coordinación Democrática de Salamanca y de Castilla y León, en torno al cual se generó un proyecto de crear un Partido Democrático Regionalista; cuestión que fue objeto de debate interno en varias ocasiones y quizás estuvo en el origen de la Candidatura Independiente - con un claro programa regionalista - de su lider salmantino, el Prof. José Luis Martín , al Senado en la convocatoria de 1979 , quién alcanzó 18.494 votos $(9,33 \%)$; sobre la que existe variada documentación (planes, artículos de opinión, publicística, etc). A raíz de esa campaña, en las primeras elecciones locales de 1979, esta sección provincial del IRCL asesora y apoya a las candidaturas progresistas en los municipios. Sin embargo, su actividad languidecerá rápidamente a lo largo de los ochenta ${ }^{26}$.

Vinculado a miembros de esta organización se dio vida, aunque efímera, a un ambicioso proyecto cooperativo, aglutinado en torno a la Caja Laboral y Empresarial de Salamanca de la que se conservan los Estatutos, Circulares, Balances anuales y Memorias correspondientes a los años

26. Su ideario puede seguirse a travès de las publicaciones: Documentos sobre regionalismo, Municipio y Regionalismo, Salamanca, 1979. Martin Rodríguez, J. L. Escritos politicos (del Referendum a las elecciones locales), Salamanca, 1979. 
1979 y 1981, programas de seminarios económicos de formación cooperativa y su órgano de expresión, la Revta. Cónclave.

Finalmente, queremos destacar que el ideario regionalista del IRC-L nunca propició, ni se presentó, como reacción irredentista o nostálgica de Castilla ante los nacionalismos. La prueba de ello son dos hechos: el titular del archivo que reseñamos fue Vicepresidente primero de la Junta Directiva de la Asociación Española de Ciencia Regional (mandato Presidencial de TRIAS FARGAS), encontrándose fondos interesantes pertenecientes a esta entidad y, en menor medida, de la Sociedad Asturiana de Estudios Industriales (SADEI). También se mantienen fluidas relaciones con la $l^{a}$ Asamblea de Intelectuales y Artistas del Estado Español (Barcelona, 15-16 de enero de 1977).

Si puede quedar la incógnita de la influencia real del IRC-L en la construcción autonómica, señalemos que la mayoría de sus fundadores y miembros pertenecian a las denominadas clases urbanas intermedias de peso decisorio en Castilla y León. Además, hubo trasvase de cuadros entre esta entidad y los partidos parlamentarios (UCD ,PSOE, PCE), diseñadores del mapa final de la Comunidad, prácticamente idéntico al que proponía el IRC-L.

\section{BIBLIOTECA-HEMEROTECA DE CASTILLA Y LEÓN Y DE LAS AUTONOMIAS ESPAÑOLAS}

Los fondos contenidos en este centro son el resultado del ilusionado esfuerzo del Profesor burgalés Dr. D. Federico Pérez, quien desde 1974 viene trabajando para reunir cuanto se publica en y sobre Castilla y León.

Puede decirse que esta biblioteca-hemeroteca es la más importante en su género en la región, pues hasta el momento presente posee unos 12.000 libros y folletos, una colección de 470 revistas y periódicos, así como una selección de 40.000 artículos de prensa.

En general, este material es variadísimo, pues ha sido reunido tanto mediante adquisiciones de su propietario, como a través de donaciones que durante años le han sido hechas por particulares, instituciones y editoriales. En uno u otro caso, se trata de todo aquello que de alguna manera tiene que ver con Castilla y León.

El fondo bibliográfico es particularmente rico en historia y en cuanto se relaciona con Castilla como problema, desde el 98 hasta la actividad publicístico-política de la Transición y la autonomía. 
Dentro del fondo bibliográfico se encuentran todas aquellas ediciones que tienen formato de folleto, tales como Estatutos de partidos, sindicatos o cooperativas y Reglamentos o Boletines de entidades diversas. También se halla gran número de publicaciones, referentes a los distintos efectos sobre la región de la vinculación de España a la Unión Europea.

Por lo que hace al fondo hemerográfico, en el que se encuentran también publicaciones de ámbito nacional, hay que señalar que su gran número deriva de lo efímero de algunas cabeceras y de que en muchos casos las colecciones no son completas. Este límite queda en parte suplido por la selección de los 40.000 artículos de prensa, convenientemente ordenados y clasificados.

Entre este material se encuentran también diversas hojas volanderas y panfletos de variada tendencia y referentes a los distintos problemas que han agitado ocasionalmente a la opinión pública de la región.

Además del fondo bibliográfico y hemerográfico, existe en la entidad que nos ocupa un fichero donde se ordenan los materiales recopilados y que, incluso, también almacena información sobre publicaciones existentes pero que aún no posee el centro.

El presente trabajo no habría sido posible sin la eficaz colaboración de las personas y entidades que custodian los fondos que hemos reseñado. A la vez que les mostramos públicamente nuestro reconocimiento, pensamos que sería muy interesante que las instituciones regionales realizasen un inventario completo de todos aquellos archivos - públicos y privadosexistentes en Castilla y León, que contengan fuentes para nuestra historia más reciente. 